\title{
A iatrogenia nas desordens temporomandibulares e dores oro-faciais
}

Prof. Tit. Dr. Eleutério Araújo Martins Profa. Rejane Nunes

\section{RESUMO}

É realizada uma discussão sobre as informaçōes disponíveis a partir de pesquisas atuais, publicadas na literatura. São também analisadas as suas consequências na determinação de avanços clínicos no reconhecimento das várias etiologias capazes de desencadear desordens temporomandibulares e dores oro-faciais.

Uma ênfase especial é dada à necessidade de uma base biológica ampla e correta, e à apresentação - tão cedo quanto possível no curso pré-clínico - de informaçāo relativa a pesquisas clínicas selecionadas, de maneira a prover um real embasamento a um profissional que deve, crítica, analítica e cientificamente avaliar e coordenar tratamentos em pacientes com desordens temporomandibulares e dores oro-faciais.

Um diagnóstico absolutamente correto é a precípua, e quem sabe o único meio conhecido de ser evitada a iatrogenia.

\section{SUMMARY}

Informations obtained from recent research beeing published in the literature are discussed. There are also annalyzed their possibilities in determining clinical advances in the recognition of the various possible etiologies of temporomandibular joint desorders and oro-facial pains.

Special emphasis is given to the need of a sound and wide biological background, and to the presentation as soon as possible in the pre-clinical course of selected clinical research results, in order to provide the main substract to a professional that must, critically, annalytically and scientifically, manage patients with TMD and oro-facial pains.

An absolutelly correct diagnosis in the main basis, and perhaps the only known way to avoid iatrogenics.

\section{IATROGENIA}

Alteraçăo patológica provocada no paciente por tratamento errôneo ou inadvertido. Por errôneo se deve entender também o tratamento insuficiente para promover a cura.

Mesmo não sendo aconselhável num simpósio, discussão aprofundada de pesquisas científicas atualizadas, é entretanto absolutamente imprescindivel que sejam bem esclarecidas a sua influência e sua importância nas terapias a serem adotadas neste início dos anos 90 , bem como a capacitação dos profissionais da saúde em absorvê-las.

Em sua grande maioria, os tratamento oferecidos pelos dentistas, atualmente, estão dentro de quatro categorias gerais:

1. tratamentos dirigidos aos dentes
2. tratamentos dirigidos aos músculos

3. tratamentos dirigidos às ATM's

4. tratamentos dirigidos ao SNC

$\mathrm{Em}$ todas as quatro situaçōes existem três possíveis hipóteses de iatrogenia, a saber:

a. tratamentos incorretamente indicados

b. tratamentos incorretamente realizados

c. tratamentos bem indicados, bem realizados mas insuficientes, de per si, para a eliminação completa do fator causal, permitindo sua evolução.

O tratamento e o controle da dor aguda, na maior parte dos casos, raramente é um problema. Entretanto, quando os sintomas da dor persistem muito depois de a injúria ter de- saparecido, e parâmetros psicológicos influenciam as respostas do paciente, seu tratamento e controle se tornam complexos: podem variar de uma monoterapia a uma terapia multidisciplinar, chegando às vezes ao charlatanismo (1).

As controvérsias existentes entre as profissōes médicas e dentária extrapolam muitas vezes os limites da discussão científica limitada e atin-

Trabalho apresentado no Simpósio II do XIV Congresso Paulista de Odontologia - Janeiro, 1990 - São Paulo.

IATROGENIA DA DISFUNÇĀO

(T.M.J. - Disfunctions \& Disorders - IATROGENIC CAUSES)

Simposiastas (member of the Symposium)

Jeffrey P. Okeson - U.S.A.; Eleutério Martins -

Brasil; Carlos Marholz Oróstegui - Chile; Julio

César Turrel - Uruguai. 
gem o grande público através dos meios de divulgação leigos. São comuns em alguns meios de comunicação manchetes tais como: "A doença da década", "90\% da população estăo atingidos pela doença da moda". Outro exemplo: no exemplar de 25 de abril de 1988, a revista TIME (EE.UU.) apareceu um artigo intitulado "Tratando a doença da moda". Nesse artigo a referência era para Desordens Temporomandibulares, uma doença afetando, segundo o texto, 10 milhões de americanos e caracterizada por "controvérsias a respetito da importância da doença", "sintomas tăo variáveis que o diagnóstico se torna difícil", "sem cura única garantida", "de maneira que qualquer um - de cirurgiōes a charlatảes - se sentem aptos a oferecer terapia". Essas afirmativas são altamente preocupantes para aqueles que tratam seriamente do problema. Palla disse a respeito: "para mim, como professor e pesquisador, 0 artigo indica que as universidades faIharam em formar dentistas que fossem CRÍTICOS, ANALÍTICOS e CIENTÍFICOS em sua abordagem a pacientes com desordens temporomandibulares. Dessa maneira, muitos e muitos profissionais usam modalidades de tratamento que nunca foram validadas cientificamente, que são carentes de dados de acompanhamento a longo prazo e que, além do mais são invasivas, caras e irreversíveis. Essas modalidades são justificadas, muitas vezes, pelo resultado final de sucesso clínico. Lamentavelmente, isso apenas ajuda a reforçar uma hipótese de diagnóstico pré-concebida, e não a provar cientificamente uma relaçăo de causa $e$ efeito (2)".

A odontologia por certo evoluiu desde os anos trinta, quando os primeiro esforços dirigidos ao problema das desordens temporomandibulares eram todos orientados no sentido dos dentes. Os anos 40,50 e 60 trouxeram a ampliaçăo das bases de diagnóstico e tratamento, com o reconhecimento das etiologias miogênicas, artrogênicas e neurogênicas.
Os anos 70 e 80 testemunharam a incorporação dos fatores psicogênicos e o envolvimento da tensão (3).

Em um passado não muito distante, os dentistas frequentemente tratavam o paciente de "ATM" com coronoplastia ou com a colocação de uma cobertura oclusal plástica que deviam alterar uma relação maxilomandibular. 0 procedimento seguidamente prescrito, parece que era limitado pela experiência de diagnóstico e terapêutica do profissional. Presentemente, em Odontologia, há uma grande necessidade por uma melhor compreensão dos pacientes com um largo espectro de sintomas de ATM, desordens temporomandibulares, disfunçōes de dor e miofasciais, disfunçōes mandibulares, nevralgias faciais atípicas e outras. Nesse campo há ainda muitas áreas de sombra e ignorância (4).

Depois de muitas tentativas de se estabelecer quais os sinais e sintomas que poderiam caracterizar uma situação a ser tratada (prevalência da patologia) onde não faltaram levantamentos epidemiológicos os mais variados, baseados na identificação de fatores supostamente afastados da normalidade, parece que neste início dos anos 90 há um consenso quanto ao fator primordial a merecer atenção e terapia: a DOR. As classificações das dores que ocorrem na região oro-facial, são inúmeras. Quanto às suas causas ou locais de origem, podem ser agrupadas em:

1. das estruturas orais

2. das estruturas músculo-esquelética
3. neurológicas
4. otorrinolaringológicas
5. oftalmológicas
6. de neuplasias
7. psicogênicas
8. de deaferentação
9. vasculares $e$,

10. de outras causas sistêmicas

Há necessidade, portanto, de diagnóstico etiológico cuidadoso, afim de direcionar corretamente a terapia, incluindo-se aí a separação acurada de problemas temporoman- dibulares, neuro-musculares e temporomandibulares associados, exclusivamente musculares, e a identificação de todo um complexo multifatorial seguidamente presente. Há consenso geral de que a dor, antes de mais nada, se constitue em uma experiência complexa, multifatorial, que abrange dimensões sensoriaisdiscriminatórias, afetivas (emocionais), cognitivas e motivacionais.

$A$ identificação de um mecanismo descendente inibitório, permanentemente atuante e, aparentemente originado em centro supra-espinhais, mais a descoberta do sistema antinociceptivo endógeno, há 15 anos, abriram novos caminhos na compreensão e tratamento da dor.

Os estudos mais recentes se relacionam, basicamente, com metodologias apropriadas para investigar os mecaniosmos da dor aguda. Alguns desses mecanismos, sem nenhuma dúvida, estão também envolvidos na dor crônica, mas as bases patofisiológicas da nevralgia do trigêmio, da dor facial atípica, das dores miofasciais e de disfunção da ATM, a xerostomia e outras condiçōes de dor clínica que se manifestam na região oro-facial, ainda são bastante hipotéticas em alguns casos.

Parece inegável que este momento é de importância capital para uma definição clara de posicionamento científico no que se refere ao que nós, como professores, temos a obrigação de transmitir e, ao final, exigir de nossos alunos, pois seremos inexoravelmente responsáveis pelas terapias que eles estarão aptos ou não a oferecer a seus pacientes. Nossa postura só pode ser a de acompanhamento imediato e sistemático das pesquisas atualmente em execução, das quais alguns exemplos são o estabelecimento e identificação de modelos geradores centrais dos movimentos cíclicos da mandíbula (5), da deaferentação e seus reflexos na arquitetura do complexo sensorial trigeminal da raiz cerebral (6), bem como de investigações relacionadas com a transmissão e modulação da dor em vá- 
rios níveis (7). A pesquisa básica neurofisiológica, a cada dia, impōe restriçōes a terapias baseadas apenas em hipóteses nunca comprovadas além de confrontar a nós, dentistas, com um desafio que nossa formaçăo básica não permite, seja enfrentado isoladamente. Assim, dores de cabeça, condiçōes artríticas e músculo-esqueléticas crânio-faciais, na maioria das vezes, para seu tratamento vão requerer consultoria, apoio e tratamento médicos. Algumas dores săo consequências de medidas terapêuticas (8). Apesar de esta situaçăo poder estar relacionada com efeitos modulares determinados pela maneira de abordagem, há ocasiōes em que uma terapia dentária ou mastigatória diretamente inicia um processo doloroso. Tratamentos adotados, baseados em diagnósticos incorretos ou incompletos, podem terminar dessa maneira. Uma terapêutica aplicada no local de uma dor heterotópica ao invés de no local de origem da dor, pode causar injúria ou ainda permitir, por outro lado, um desenvolvimento do fator causal até uma situação de alto risco.

Desgastes oclusais mal indicados e realizados podem aumentar a sensibilidade dos dentes. Alteraçőes das relaçōes oclusais por coronoplastias, prótese, dentística restauradora, ortodontia e outros meios, podem comprovadamente inciar dor, envolvendo músculos e articulaçōes temporomandibulares bem como dentes e estruturas periodontais.

Deve estar presente o fato de que qualquer procedimento - mesmo corretivo e, sob outros aspectos, benéfico que altere a aferência proprioceptiva e sensorial, pode iniciar uma dor devido à estabilização muscular protetora (muscle splinting), a qual, se não controlada adequadamente, pode evoluir para um mioespasmo ou uma miosite.

Mudanças rápidas nas relaçőes funcionais ou uma incorreta seleção do tratamento, podem dar lugar a uma condiçăo que tenha um componente de dor.
Alguns procedimentos que determinem a interrupção cirúrgica de trajetórias nociceptivas podem gerar sequelas irreversíveis, as quais podem até superar o possivel benefício terapêutico buscado. A deaferentaçăo parece, no momento, ser uma das causas possíveis etiológicas das dores crônicas oro-faciais, em alguns casos. Se nos parece cabível então a colocação clara e objetiva de algumas questōes que devem, obrigatoriamente ter resposta, como:

1. Há uma consciência coletiva das relações de causa e efeito dos tratamentos regularmente executados pelos cirurgiōes dentistas?

2. Terão os endodontistas plena consciência e/ou conhecimento das alterações que provocam estruturalmente, a nível do sub-núcleo oralis do complexo sensorial trigeminal da raiz cerebral, quando realizam pulpotomias e que isto pode estar relacionado com algumas das dores crônicas oro-faciais?

3. Sabem os cirurgiōes que, mesmo em cirurgias orais menores, pode ocorrer a formaçăo de um neuroma traumático, eventuais efapses e presença de dor, posteriormente?

4. Têm os cirurgiões dentistas, plena consciência das alteraçōes que podem ocorrer no campo receptivo dos mesmos, quando da lesão de neurônios periféricos? E do estabelecimento de novas trajetórias nociceptivas por meio de neurônios que não são cociceptivos específicos e que têm seu campo receptivo e/ou seu limiar de excitabilidade diminuído?

5. Que alteraçōes, mesmo mínimas, nos mecanismos sensoriais orais e faringeanos podem determinar alteraçōes nos movimentos rítmicos da mandíbula?

6. Que a apomorfina (agonista da dopamina) pode determinar o desencadeamento de movimentos rítmicos da mandíbula, e que a serotonina $(5 \mathrm{HT})$ - sinérgica da dopamina - está ao que parece intimamente relacionada com a qua- lidade do sono e, por extensão, ao bruxismo noturno?

7. Que, comprovadamente, esforços alterados sobre os dentes provocam alteraçōes nas secreçōes endócrinas (9) e reflexos na memória, em humanos (10)?

Trazido isto à apreciação coletiva cabem as seguintes indagações:

1. O embasamento científico que estão recebendo os cirurgiōes dentistas em seus cursos de graduação nas Faculdades de Odontologia e nos organismos responsáveis pelo ensino continuado (pós-graduação) é adequado e suficiente?

2. As organizações profissionais responsáveis por cursos de pequena duração (atualização) e, o que é mais importante, pela liberaçăo de informaçăo ao grande público, mantém uma linha cientificamente atualizada?

Lamentavelmente, em muitos casos a resposta parece ser negativa. $E$ isso nos encaminha para o início desta abordagem: tratamento errôneo ou inadvertido. Onde repousa o fator que determina maus tratamentos, tratamentos insuficientes, em suma, iatrogenia?

É importante que se atente bem para três citaçōes que faço, na íntegra:

$1^{\circ}$ - "Nossas Faculdades de Odontologia deveriam oferecer ao clínico, ed ıcação continuada nos tópicos referentes a desordens temporomandibulares. As últimas tentativas de educação continuada não foram adequadamente atingidas em seus objetivos pela organização dental autorizada, e seguidamente o que testemunhamos é o equivalente em Odontologia, aos evangelistas religiosos da televisão, que operam sob uma "economia de quintal" e montam fortunas pessoais" (11).

$2^{\circ}$ - "Ao invés de permitir que os dentistas tomem cursos com 'autoridades em articulação temporomandibular' deveríamos orientá-los mais racionalmente. Deveríamos fazer um trabalho mais consciente em educar dentistas para que fossem discipli-
R. Fac. Odontol.

Porto Alegre

V. 32

N. 2

p.36-39

NOVEMBRO

1991 
nadamente treinados para exercitar uma análise crítica e analítica das informaçōes que recebem. Necessitamos encorajar e patrocinar investigaçőes científicas rigorosas sobre o tema. Necessitamos de revistas especializadas honestas, que mantenham a profissão responsavelmente informada e a realizaçăo de reuniōes científicas onde as idéias sejam APRESENTADAS, DOCUMENTADAS e INTERPELADAS, ao invés de serem comercializadas para lucro $e$ prestígio" (12).

$3^{\circ}$ - "O tratamento das síndromes de dor oro-facial crônicas é comple$x o$, exigindo maiores conhecimentos e perícia em farmacologia clínica, ciências básicas e clínica médica, como por exemplo, neurologia, otorrinolaringologia e fisioterapia. Os dentistas seguidamente podem ser confrontados ou envolvidos no diagnóstico e orientaçāo de muitas outras síndromes que incluem nevralgias do trigêmio, paralisia de Bell, queimação de língua e boca, neuromas traumáticos, dores faciais atípicas e dores de cabeça. É uma área da odontologia que, quando exercida com competência, preenche o espaço de credibilidade médica e permite ao dentista trabalhar usando princípios médicos básicos. Desafortunadamente, este não é o caso. Quase sempre os currículos das Faculdades de Odontologia são provincianos (limitados) e consumidos com a parte mecânica da Odontologia. Muitos dos tratamentos realizados são altamente questionáveis, refletindo os processos de um pensamento mecânico, ao invés de uma abordagem baseada em dados científicos" (13).

Todas as três são de eminentes educadores dos Estados Unidos, conforme se pode ver nas referências bibliográficas. Mas creio que também se aplicam ao nosso País, tanto pelo seu conteúdo como por sua atualidade.

Parece assim, bastante claro, que a não ser por má fé, a iatrogenia tem seu embasamento maior na deficiência de o cirurgião dentista estabelecer um diagnóstico correto e completo, em se tratando de problemas relativos a desordens temporomandibulares e síndromes de dor oro-facial. Na grande mudança de rumos que devemos enfrentar, nossos currículos dentais devem incluir cursos que promovam o conhecimento e a compreensão das ciências básicas, necessários para o reconhecimento específico e lógico da função estomatognática normal. Adicionalmente, os conhecimentos necessários para a capacitação de estabelecer um diagnóstico clínico de uma função alterada, devem incorporar os do funcionamento de todos os sistemas que porventura estejam envolvidos ou possam contribuir para a disfunção. Isto, NECESSARIAMEN$T E$, é uma extensão muito além dos dentes e da oclusão dentária (11). Para o futuro imediato, devemos estabelecer um consenso amplo e majoritariamente aceito, daquilo que nós dentistas, estamos atualmente diagnosticando e tratando sob a proteção do grande guarda-chuva chamado "problemas temporomandibulares". Há necessidade de reconhecimento e identificaçăo das diversas etiologias e da indicação de procedimentos terapêuticos para cada uma delas. Nos próximos anos assistiremos a uma tremenda mudança na seleção dos tratamentos relativos a desordens temporomandibulares e síndromes de dor oro-facial, face ao aporte quase diuturno de novas pesquisas. Os dentistas, OBRIGATORIAMENTE, deverão estar preparados para avaliar criticamente a informação atualizada e aplicar corretamente suas decorrências clínicas.

No momento parece haver consenso geral a respeito de duas coisas:

1. os pacientes com problemas de DTM e dor oro-facial devem receber tratamento a nivel dentário, NUNCA MENOS que perfeitos; $e$ 2. a abordagem inicial SEMPRE deve ser não-invasiva e reversível. Pelo menos, năo lese.

Parece não haver dúvidas que, nos dias de hoje, o maior potencial para que haja iatrogenia reside na incapacidade dos dentistas, insuficientemente preparados, para estabelecer um diagnóstico diferencial etiológico correto. Os tratamentos equivocados e prejudiciais são apenas, e năo mais do que, uma decorrência sequencial.

\section{REFERÊNCIAS \\ BIBLIOGRÁFICAS}

01. CURRO, F.A. - Assessing the physiologic and clinical characteristics of acute versus chronic pain. Dent. Clin. North. Am. Vol. 31, No 4, p.XIII, Oct., 1987.

02. PALLA, S. - Editorial. J. Craniomand. Disord. Facial Oral Pain. Vol. 2, No 3, p.115, 1988.

03. PERRY, H.T.Jr. - Editorial. J. Craniomand. Disord. Facial Oral Pain. Vol. 3, No 3 , p.119, 1989.

04. PERRY, H.T.Jr. - Editorial. J. Craniomand. Disord. Facial Oral Pain. Vol. 2, No 1, p.4, 1988.

05. DAVIDSON, R.M. \& MOHL, N.D. - Sensory and motor integration during mandibular function. Dent. Clin. North. Am. Vol. 31, $N^{\circ} 4$, p.615-26, Oct., 1987.

06. SESSLE, B.J. - The neurobiology of facial and dental pain: present knowledge, future directions. J. Dent. Res. 66:962-81, 1987.

07. AIMONE, L.D.; JONES, S.L.; GEBHART, G.F. - Stimulation produced descending innibition from the periaqueductal gray and nucleus raphe magnus in the rat: mediation by spinal monoamines but not opioids. Pain. 31:123-6, 1987.

08. BELL, W.E. - Oro-facial pains. 4th Ed., Year Book Medical Publishers, XXII+448 pg., p.93, 1989.

09. WALKER, J.A.; TANZER, F.S.; HARRIS, E.F.; WAKELIN, C.; DESIDERIO, D.M. The enkephalin response in human teeth to orthodontic force. Am. J. Orthod. Dentofacial Orthop. 92:9-16, 1987.

10. NUNES, R. \& MARTINS, E.A. - Orthodontic-like forces and memory. Studies in humans. (In press)

11. PERRY, H.T.Jr. - Editorial-Chairman - J. Craniomand. Disord. Facial Oral Pain. Vol. 3, No 3, 1989.

12. STOREY, A.T. - Editorial. J. Craniomand. Disord. Facial Oral Pain. Vol. 1, No 3 , 1987.

13. CURRO, F.A. - Assessing the physiologic and clinical characteristics of acute versus chronic pain. Dent. Clin. North. Am. Vol. 31, N 4, p.XXI, Oct., 1987. 